\title{
May serum tests help in selecting patients for a regastroscopy?
}

\author{
Oksanen Aino, M*, Paloheimo Lea ${ }^{2}$, Rautelin Hilpi ${ }^{3}$
}

${ }^{1}$ Malmi Hospital, Talvelantie 6, 00700 Helsinki, Finland.

${ }^{2}$ Biohit Oyj, Laippatie 1, 00880 Helsinki, Finland.

${ }^{3}$ Department of Medical Sciences, Clinical Microbiology, Uppsala University, Uppsala, Sweden, and Department of Bacteriology and Immunology, University of Helsinki, Finland.

Corresponding Author: Aino Oksanen, MD PhD, Malmi Hospital, Talvelantie 6, 00700 Helsinki, Finland, tel 358-9-3106611. E-mail: aino.oksanen@hel.fi

\begin{abstract}
Objective: We have previously shown that the presence of abnormal macroscopical findings at earlier gastrocopy was among the best indicators of abnormal macroscopical findings at regastroscopy.

In the present study we evaluated whether serum tests could help to select patients with for regastroscopy.

Materials and Methods: Serum H. pylori antibodies of the IgG class, pepsinogens I and II, and gastrin -17 were analyzed for 190 patients without alarm symptoms undergoing regastroscopy. For 126 patients, an earlier gastroscopy report showing a normal finding was available. Associations between serum tests and macroscopical and histological findings at gastroscopy were analyzed.

Results: If patients with normal earlier gastroscopy had been selected for regastroscopy on basis of positive H. pylori serology or low pepsinogen I, 82 of the 126 gastroscopies performed (65\%) would have been saved. However, in that case 19/25 patients with an abnormal macroscopical finding and four of 17 patients with moderate or severe atrophic gastritis had been missed. If patients had been selected for regastroscopy on the basis of positive $H$. pylori antibodies, low pepsinogen I, or low serum gastrin-17, 57 gastroscopies (45\%) had been saved, but still 13/25 with an abnormal macroscopical finding and two of 17 patients with atrophic gastritis would have been missed. Macroscopical findings and isolated atrophic gastritis of the antrum could not be detected by serum tests.

Conclusions: Among typical patients in Western countries, with a low prevalence of $H$. pylori infection and atrophic gastritis, usefulness of serum tests to select patients for regastroscopy is limited.
\end{abstract}

Keywords: Regastroscopy; Atrophic Gastritis; Helicobacter pylori; Pepsinogens; Gastrin-17

\section{Introduction}

Various strategies, such as those based on patients' symptoms or serum test results, have been developed to screen dyspeptic patients for gastroscopy. Helicobacter pylori (H. pylori) causes gastritis and is the most important risk factor for peptic ulcer disease and gastric cancer ${ }^{[1]}$. The presence of $H$. pylori can easily be detected by serology ${ }^{[2]}$, although $H$. pylori antibody titres may remain elevated even for years after succesful eradication therapy ${ }^{[3]}$. Pepsinogen I (PG I) is secreted in the corpus mucosa in oxynthic glands, whereas pepsinogen II (PG II) is secreted from both the oxynthic glands and from the pyloric glands in the antrum ${ }^{[4]}$. Oxynthic glands disappear in atrophic corpus gastritis, and thus, low serum PG I level or decreased PG
Received Date: July 27, 2015

Accepted Date: August 14, 2015

Published Date: August 20, 2015

Citation: Oksanen et al. May serum tests help in selecting patients for a regastroscopy? (2015) J Gastrointest Disord Liver Func 1(1): 7- 10.

I/II ratio reveal severe atrophic gastritis of the corpus. Gastrin consists of at least two bioactive forms, gastrin-17 (G-17) and gastrin-34. G-17 is secreted from the antrum and stimulated by a meal, whereas gastrin-34 is mainly secreted from the duodenum. Accordingly, low serum G-17 levels have been associated with atrophic gastritis of the antrum ${ }^{[5,6]}$. The combination of positive $H$. pylori serology, low PG I and low G-17 has been introduced to screen patients before gastroscopy ${ }^{[7]}$.

H. pylori infection has an impact on serum levels of PG I and G-17 in several ways. Patients with H. pylori gastritis have higher serum PG I and PG II levels and lower PG I/II ratio than H. pylori negative individuals ${ }^{[8]}$; but in the presence of atrophic corpus gastritis which often develops in H. pylori positive individuals, the serum level of PG I decreases $^{[9]}$. In H. pylori gastritis serum G-17 is increased and it decreases after eradication of the infection ${ }^{[10]}$. However, in severe corpus atrophy serum gastrin levels increase because of the achlorhydria $^{[5]}$. Also the use of proton pump inhibitors (PPIs) increases serum gastrin levels ${ }^{[11]}$. 
The discovery of $H$. pylori has totally changed our understanding of many gastrointestinal diseases. However, the prevalence of $H$. pylori infection is now rapidly decreasing in the Western world ${ }^{[12]}$, and the majority of findings at gastroscopy are not necessarily related to $H$. pylori or atrophic gastritis any more. Although a repeat gastroscopy is not recommended if alarm symptoms are not present ${ }^{[13]}$, regastroscopy might be requested by primary care doctors to reassure dyspeptic patients with fluctuating symptoms. We have recently shown that, in a typical Western population with a low prevalence of $H$. pylori infection, an abnormal macroscopical finding at an earlier gastroscopy was, along with the presence of alarm symptoms and obesity, the strongest indicator for an abnormal finding at a repeat gastroscopy ${ }^{[14]}$.

The present study was performed in order to evaluate whether serum tests could be used, instead of a repeat gastroscopy, to reassure patients with no alarm symptoms. We calculated how many gastroscopies would have been saved, and what would have been missed if the repeat gastroscopy had not been performed for patients with a normal finding at an earlier gastroscopy and normal serum test results.

\section{Patients and methods}

A total of 190 consecutive patients, who were gastroscopied at Herttoniemi hospital in 2004-2005, donated a blood sample. The patients included participated in our earlier study ${ }^{[14]}$, and had no alarm symptoms. Patients with previous gastric surgery were excluded. The median age of the patients was 64 years (range $24-87$ years), and 142 (75\%) were women. Patient records were searched for $H$. pylori tests and performed eradication treatments, as well as for use of PPIs.

Patients underwent gastroscopy with two biopsies taken from the antrum and the corpus. The biopsies were analysed according to the revised Sydney system ${ }^{[15]}$ by one pathologist, who was unaware of the results of the serum tests. H. pylori culture was performed as clinically indicated. H. pylori positivity was defined as positive histology and/or positive culture.

The serum samples were stored at $-20^{\circ} \mathrm{C}$ and analyzed for $H$. pylori antibodies of the IgG class by an in-house enzyme immunoassay ${ }^{[2]}$; antibody titres $<700$ were considered normal. Serum PG I, PG II, and G-17 were analyzed with GastroPanel kit (Biohit Oyj, Helsinki, Finland) by the manufacturer. The normal limits were the following: for PG I 30-65 $\mu \mathrm{g} / \mathrm{l}$, for PG II 3-10 $\mu \mathrm{g} / \mathrm{l}$, and for G-17 2-10 pmol/1, respectively.

The study was approved by the Ethical Committee for Internal Medicine in Helsinki University Central Hospital. All patients gave a written informed consent. Differences between the groups were evaluated by Fischer's exact test, and $p<0.05$ was considered statistically significant.

\section{Results}

A total of 43 of the 190 patients (23\%) had an abnormal macroscopical finding other than hiatal hernia. These findings mostly consisted of mild (LA grade A-B) oesophagitis or erosive gastritis ${ }^{[14]}$. Six patients had a macroscopical finding defined as severe: four had benign prepyloric ulcers; one had severe oesophagitis, and one Barrett's oesophagus of $10 \mathrm{~cm}$ length. Of these particular patients, three patients with ulcer and the only patient with severe oesophagitis had positive $H$. pylori antibodies; the remaining two patients had normal serum test results. As shown in Table I, there was no significant association between the presence of abnormal macroscopical findings and the results of serum tests except for the inverse association of low serum PG I and the presence of abnormal macroscopical findings. Patients' use of PPIs was associated with serum G-17 levels: twenty of 54 patients with no PPI use for at least a month had low G-17, whereas only three patients of 23 with regular PPI use for a month before the gastroscopy had low serum G-17 $(p=.03)$.

Table 1: Results of serum tests for patients with abnormal versus normal macroscopical findings at gastroscopy. Number of patients with severe findings are shown in parenthesis.

\begin{tabular}{|c|c|c|c|}
\hline \multirow[t]{2}{*}{ Serum test results } & \multicolumn{2}{|c|}{$\begin{array}{l}\text { Number of patients with macroscop- } \\
\text { ical finding }\end{array}$} & \multirow[t]{2}{*}{$\mathrm{P}$} \\
\hline & $\begin{array}{c}\text { abnormal } \\
\text { all (severe), } n=43(6)\end{array}$ & $\begin{array}{c}\text { normal } \\
\mathrm{n}=147\end{array}$ & \\
\hline $\mathrm{IgG}^{\mathrm{a}}>700$ & $12(4)$ & 42 & \multirow[t]{2}{*}{1.0} \\
\hline $\operatorname{IgG}^{\mathrm{a}}<700$ & $31(2)$ & 105 & \\
\hline PG I ${ }^{\mathrm{b}}<30 \mu \mathrm{g} / 1$ & 0 & 13 & \multirow[t]{2}{*}{0.04} \\
\hline $\mathrm{PG} \mathrm{I}^{\mathrm{b}}>30 \mu \mathrm{g} / 1$ & $43(6)$ & 134 & \\
\hline G-17c $<2$ pmol/1 & $14(0)$ & 39 & \multirow[t]{2}{*}{0.44} \\
\hline $\mathrm{G}-17^{\mathrm{c}}>2 \mathrm{pmol} / 1$ & $29(6)$ & 108 & \\
\hline
\end{tabular}

$\mathrm{a}=$ serum H. pylori antibodies of the IgG class

$\mathrm{b}=$ serum pepsinogen $\mathrm{I}$

$\mathrm{c}=$ serum gastrin -17

The prevalence of $H$. pylori infection was low. Only 20 (11\%) of the 190 patients had an ongoing H. pylori infection: 19 patients were positive for $H$. pylori in histology, and one further patient had positive $H$. pylori culture; all but one of these patients had positive $H$. pylori serology. In addition, 68 patients had a history of a previous $H$. pylori eradication; 28 of these still had positive $H$. pylori serology. Seven further patients had only positive $H$. pylori serology, antibody titres ranging from 900 to 1600 . Thus, a total of 95 patients $(50 \%)$ had signs of an ongoing or previous $H$. pylori infection. Of those with positive $H$. pylori serology 19/54 (35\%) had an ongoing infection.

Of all the 190 patients, 123 (65\%) had histologically normal gastric mucosa, as defined as mild or no chronic gastritis and neither $H$. pylori nor atrophy or intestinal metaplasia in the antrum or in the corpus. Of these 123, none had low serum PG I, $20(16 \%)$ had positive $H$. pylori serology, and 69 further patients (56\%) had low serum G-17 (<2 pmol/1).

A total of 24 patients $(13 \%)$ had moderate or severe (grade 2 or 3 ) atrophic gastritis either in the antrum or in the corpus. Of the 11 patients with moderate or severe atrophic gastritis in the antrum, two had also mild (grade 1) atrophic gastritis of the corpus, while the rest had no atrophic gastritis of the corpus. Of the 13 patients with moderate or severe atrophic gastritis of the corpus none had any atrophic changes in the antrum. Thus, not a single patient had panatrophy, as defined as moderate or severe atrophic gastritis both in the antrum and in the corpus. Two patients with moderate or severe atrophic gastritis in the antrum had an ongoing $H$. pylori infection, and the other nine patients had a history of an eradication treatment, while no patient with atrophic corpus gastritis was histologically $H$. pylori positive at 
the gastroscopy, and only one had a history of $H$. pylori eradication treatment.

Low PG I detected all but one of the patients with grade 2-3 atrophic corpus gastritis $(\mathrm{p}<0.0001) ; H$. pylori serology was not positive for any of them. Fourteen patients had PG I/II ratio under 3; of these 13 had also low PG I, and 12 had severe corpus atrophy. All eleven patients who had PG I/II ratio under 2, 5 had also low PG I and severe corpus atrophy. As shown in Table II, no statistically significant associations were found between the results of the serum tests and atrophic gastritis in the antrum. The presence of any intestinal metaplasia in the corpus or in the antrum was significantly associated with low serum PG I ( $\mathrm{p}=$ 0.0003), showed a trend for association with positive $H$. pylori serology $(p=0.08)$ but was not associated with low serum G-17 $(\mathrm{p}=0.17)$.

Table 2: Results of serum tests for patients with or without moderate to severe atrophic gastritis of the antrum

\begin{tabular}{|c|c|c|c|}
\hline Test & $\begin{array}{l}\text { Moderate or severe } \\
\text { atrophy of the } \\
\text { antrum (11) }\end{array}$ & $\begin{array}{l}\text { Mild or no atrophy } \\
\text { of the antrum } \\
(179)\end{array}$ & $\mathrm{P}$ \\
\hline $\operatorname{IgG}^{\mathrm{a}}>700$ & 6 & 48 & \multirow[t]{2}{*}{0.08} \\
\hline $\operatorname{IgG}^{\mathrm{a}}<700$ & 5 & 131 & \\
\hline PG I ${ }^{\mathrm{b}}<30 \mu \mathrm{g} / 1$ & 0 & 13 & \multirow[t]{2}{*}{1.00} \\
\hline PG I ${ }^{\mathrm{b}}>30 \mu \mathrm{g} / 1$ & 11 & 166 & \\
\hline $\mathrm{G}-17^{\mathrm{c}}<2 \mathrm{pmol} / 1$ & 3 & 50 & \multirow[t]{2}{*}{1.00} \\
\hline $\mathrm{G}-17^{\mathrm{c}}>2 \mathrm{pmol} / \mathrm{l}$ & 8 & 129 & \\
\hline
\end{tabular}

$\mathrm{a}=$ serum $H$. pylori antibodies of the IgG class

$\mathrm{b}=$ serum pepsinogen I

$c=$ serum gastrin -17

For the 126 of the 190 patients the earlier gastroscopy had been macroscopically normal except for a possible hiatal hernia. The mean interval between the gastroscopies was 7, 9 years (range 0,6-25 years). Table III shows the number of gastroscopies that would have been saved, and the abnormal findings that would have been missed among these 126 patients, if only those with abnormal serum tests had undergone gastroscopy.

Table 3: Number of gastroscopies saved and findings missed if abnormal serum tests results had been used as indication for gastroscopy in 126 patients with a macroscopically normal earlier gastroscopy finding

\begin{tabular}{|c|c|c|c|c|c|c|}
\hline \multirow[t]{3}{*}{ Test } & \multirow{3}{*}{$\begin{array}{l}\text { Saved gas- } \\
\text { troscopies } \\
\text { (normal tests } \\
\text { results) }\end{array}$} & \multicolumn{5}{|c|}{ Missed findings } \\
\hline & & \multicolumn{2}{|c|}{$\begin{array}{l}\text { Moderate } \\
\text { or severe } \\
\text { atrophic } \\
\text { gastritis }\end{array}$} & \multirow[t]{2}{*}{$\begin{array}{l}\text { Intes- } \\
\text { tinal } \\
\text { meta- } \\
\text { plasia }\end{array}$} & \multicolumn{2}{|c|}{$\begin{array}{l}\text { Abnormal } \\
\text { macroscopi- } \\
\text { cal findings }\end{array}$} \\
\hline & & $\begin{array}{l}\text { Cor- } \\
\text { pus }\end{array}$ & $\begin{array}{l}\text { An- } \\
\text { trum }\end{array}$ & & All & $\begin{array}{l}\mathrm{Se} \\
\text { vere }\end{array}$ \\
\hline $\mathrm{IgG} / \mathrm{PG} \mathrm{I}^{\mathrm{a}}$ & $82 / 126(65 \%)$ & $1 / 11$ & $3 / 6$ & $12 / 28$ & $19 / 25$ & $2 / 6$ \\
\hline IgG/PGI/G-17b & $57 / 126(45 \%)$ & $0 / 11$ & $2 / 6$ & $9 / 28$ & $13 / 25$ & $2 / 6$ \\
\hline
\end{tabular}

$\mathrm{a}=$ only patients with serum $H$. pylori antibodies of the $\operatorname{IgG}$ class $>700$ and/or serum pepsinogen $\mathrm{I}<30 \mu \mathrm{g} / \mathrm{l}$ gastroscopied

$\mathrm{b}=$ only patients with serum $H$. pylori antibodies of the $\operatorname{IgG}$ class $>700$ and/or serum pepsinogen $\mathrm{I}<30 \mu \mathrm{g} / \mathrm{l}$ and/or serum gastrin- $17<2 \mathrm{pmol} / 1$ gastroscopied

\section{Discussion}

In this patient group with a low prevalence of $H$. $p y$ lori infection and atrophic gastritis, the abnormal macroscopical findings at regastroscopy were not detected by the serum tests used. However, in accord with earlier studies ${ }^{[16]}$, the serum tests were quite useful in exploring the histological status of the gastric mucosa. Obviously, the macroscopical findings were not associated with histological abnormalities. In addition, although low serum PG I readily detected atrophic corpus gastritis, atrophic gastritis of the antrum was not revealed reliably by any of the serum tests used. Adding low serum G-17 to the test combination of $H$. pylori antibodies and serum PG I decreased the number of missed findings, but the number of "saved" gastroscopies declined respectively.

The only association between the presence of abnormal macroscopical findings and abnormal serum tests was the negative association with low PG I. This is understandable as low serum PG I reflects achlorhydria ${ }^{[17]}$ and the majority of the macroscopical findings in our study, such as erosions in the oesophagus or stomach, are associated with the presence of acid ${ }^{[18,19]}$. H. pylori infection increases the risk for ulcer, and even for gastric erosions $^{[20]}$; however, in the present study only a minority of patients had an ongoing $H$. pylori infection, and accordingly ulcers were only few.

Patients with atrophic gastritis have an increased risk for gastric cancer ${ }^{[7]}$. Markers of atrophic gastritis could thus be used to select individuals for gastroscopy. In the present study, low serum PG I detected all except one of the patients with moderate or severe atrophic corpus gastritis. In agreement with other studies $^{[21]}$, all patients with moderate or severe antrum atrophy had signs of a present or previous $H$. pylori infection, and some of these patients were detected by positive $H$. pylori serology. Instead, the other serum tests were not helpful in detecting atrophic changes in the antrum. In an earlier study regarding a patient group with a high prevalence of $H$. pylori infection, serum G-17 level $<5 \mathrm{pmol} / 1$, instead of $<2 \mathrm{pmol} / 1$ used here, detected atrophic gastritis of the antrum with a sensitivity of $37 \%$ and specificity of $87 \%{ }^{[22]}$. The combination of positive $H$. pylori serology, low PG I or low G-17 has shown a sensitivity and specificity of $71 \%$ and $98 \%$ to detect moderate to severe corpus atrophy or panatrophy ${ }^{[21]}$, and a sensitivity and spesicifity of $40 \%$ and $94 \%$ to detect any moderate or severe atrophy ${ }^{[23]}$. The low sensitivity in detecting atrophic changes may partly be due to the obvious difficulty of the serum tests to detect atrophic gastritis of the antrum. Antrum atrophy may, however, predict an even larger risk for cancer than corpus atrophy ${ }^{[7]}$. The patients with panatrophy, described as those being at the greatest cancer risk, were however lacking in the present study. Thus, our present results may not apply to patient groups with a high prevalence of H. pylori infection and/or atrophic gastritis.

Low serum PG I or PG I/II ratio have also been succesfully used in cancer screening ${ }^{[24,25]}$. However, detecting cancer by serum tests may also have limitations. In a multicenter study, low serum PG I was associated with a risk for gastric cancer in men, but not in women ${ }^{[26]}$. Furthermore, only a part of gastric cancers are associated with atrophy. In a Japanese study, low serum PG I predicted 15/38 intestinal gastric cancers, whereas none of the patients with a diffuse cancer had low serum PG I [27]. In a Finnish study, early gastric cancer or high grade dysplasia 
was found in 14 of the 1344 smoking men who were gastroscopied because of low serum PG I. However, these 14 comprised only about $15 \%$ of all gastric cancers found within 5 years in the whole study group of 22. 436 smoking men $^{[8]}$. Also high serum G-17 levels have been shown to be associated with the presence of gastric cancer ${ }^{[29]}$ whereas, to the best of our knowledge, low serum gastrin has not so far been shown to be connected to the risk for gastric cancer.

In our study among the patients who underwent regastroscopy, the prevalence of an ongoing $H$. pylori infection was very low. Macroscopical findings were rarely severe, mostly unrelated to $H$. pylori or atrophic gastritis, and could not be detected by the serum tests. The majority of patients $(65 \%)$ had normal gastric mucosa. If patients had been screened for regastroscopy by serum tests, several patients with normal gastric mucosa and no significant macroscopical findings would have undergone gastroscopy, while some patients with severe macroscopical findings would have been missed. Although the serum tests studied might be useful among patients with high prevalence of $H$. pylori and related findings, their usefulness to select patients for regastroscopy in patient groups with a low prevalence of both $H$. pylori infection and atrophic gastritis may be limited. More studies are needed to establish the role of serum tests in the examination of dyspeptic patients in various populations.

Acknowledgement: The serum analyses for pepsinogen I, pepsinogen II and gastrin-17 were done by Biohit Oyj, Laippatie 1, 00880 Helsinki, Finland

\section{Declaration of interest:}

Aino Oksanen, Hilpi Rautelin: none. Lea Paloheimo works for Biohit Oyj.

\section{References}

1. Cover, T.,L, Blaser. M.,J. Helicobacter pylori in health and disease. (2009) Gastroenterology 136(6): 1863-73.

2. Oksanen, A., Veijola, L., Sipponen, P., et al. Evaluation of Pyloriset Screen, a rapid whole-blood diagnostic test for Helicobacter pylori infection. (1998) J Clin Microbiol 36(4): 955- 7.

3. Veijola, L., Oksanen, A., Linnala, A., et al. Persisting chronic gastritis and elevated Helicobacter pylori antibodies after successful eradication therapy. (2007) Helicobacter 12(6): 605- 8.

4. Samloff, M.I., Varis, K., Ihamäki, T., et al. Relationships among serum pepsinogen I, serum pepsinogen II, and gastric mucosal histology. (1982) Gastroenterology 83(1 Pt 2): 204- 9

5. Rembiasz, K., Konturek, P.C., Karcz, D., et al. Biomarkers in various types of atrophic gastritis and their diagnostic usefulness. (2005) Dig Dis Sci 50(3): 474- 82.

6. Cao, Q., Ran, z.h., Xiao, S.D. Screening of atrophic gastritis and gastric cancer by serum pepsinogen, gastrin-17 and Helicobacter pylori immunoglobulin G antibodies. (2007) J Dig Dis 8(1): 15- 22.

7. Sipponen, P., Graham, D.Y. Importance of atrophic gastritis in diagnostics and prevention of gastric cancer: application of plasma biomarkers. (2007) Scand J Gastroenterol 42(1): 2- 10.

8. Biasco, G., Paganelli, G.M., Vaira, D., et al. Serum pepsinogen I and II concentrations and IgG antibody to Helicobacter pylori in dyspeptic patients. (1993) J Clin Pathol 46(9): 826- 8.

9. Ohkusa, T., Miwa, H., Nomura, T., et al. Inprovement in serum pepsinogens and gastrin in long-term monitoring after eradication of Helicobacter pylori: comparison with H. pylori-negative patients. (2004) Aliment Pharmacol Ther 20(Suppl 1): 25- 32.
10. Mulholland, G., Ardill, J.E., Fillmore, D., et al. Helicobacter pylori related hypergastrinemia is the result of a selective increase in gastrin 17. (1993) Gut 34(6): 757- 61.

11. Agreus, L., Storskrubb, T., Aro, P., et al. Clinical use of proton-pump inhibitors but not H2-blockers or antacids/alginates raises the serum levels of amidated gastrin-17, pepsinogen I and pepsinogen II in a random population. (2009) Scand J Gastroenterol 44(5): 564- 70.

12. Salomaa-Räsänen, A., Kosunen, T.U., Aromaa, A.R., et al. A" Screen-and-treat" approach for Helicobacter pylori infection: A population-based study in Vammala, Finland. (2010) Helicobacter 15(1): 28- 37

13. American gastroenterological association. Medical position statement: evaluation of dyspepsia.(1998) Gastroenterology: 114(3): 579- 81. 14. Oksanen, A., Veijola, L., Korudanova, B., et al. Role of earlier gastroscopy in predicting findings on repeat gastroscopy in a population with a low H. pylori prevalence. (2008) Scand J Gastroenterol 43(9): $1044-1049$.

15. Dixon, M.F., Genta, R.M., Yardley, J.H., et al. Classification and grading of gastritis. The updated Sydney system. International Workshop on the Histopathology of Gastritis, Houston 1994. (1996) Am J Surg Pathol 20(10): 1161-81

16. Oksanen, A., Sipponen, P., Miettinen, A., et al. Evaluation of blood tests to predict normal gastric mucosa. (2000) Scand J Gastroenterol 35(8): 791- 5

17. Derakhshan, M.H., El-Omar, E., Oien, K., et al. Gastric histology, serological markers and age as predictors of gastric acid secretion in patients infected with Helicobacter pylori. (2006) J Clin Pathol 59(12): 1293- 99

18. Dent, J., Brun, J., Fendrick, A.M., et al. An evidence-based appraisal of reflux disease management - the Genval Workshop report. (1999) Gut 44 (suppl 2): S1- S16

19. Karvonen, A.L., Lehtola, J. Outcome of gastric mucosal erosions. (1984) Scand J Gastroenterol 19(2): 228- 34

20. Toljamo, K.T., Niemelä, S.E., Karttunen, T.J. et al. Clinical significance and outcome of gastric mucosal erosions: a long-term follow-up. (2006) Dig Dis Sci 51(3): 543- 7

21. Leja M, Kupcinskas L, Funka K, Sudraba A, Jonaitis L, Ivanauskas A, et al. The validity of a biomarker method for indirect detection of gastric mucosal atrophy versus standard histopathology. (2009) Dig Dis Sci 54(11): 2377- 2384

22. Storskrubb, T., Aro, P., Ronkainen, J., et al. Serum biomarkers provide an accurate method for diagnosis of atrophic gastritis in a general population: The Kalixanda study. (2008) Scand J Gastroenterol 43(12): 1448- 55

23. Iijima, K., Abe, Y., Kikuchi, R., et al. Serum biomarkers are useful in delineating between patients with gastric atrophy and normal, healthy stomach. (2009) World J Gastroenterol 15(7): 853- 9

24. Kitahara, F., Kobayashi, K., Sato, T., et al. Accuracy of screening for gastric cancer using serum pepsinogen concentrations. (1999) Gut 44: $693-7$

25. Miki, K., Morita, M., Sasajima, M., et al. Usefulness of gastric cancer screening using the serum pepsinogen test method. (2003) Am J Gastroenterol 98(4): 735- 9.

26. Webb, P.M., Hengels, K.J., Moller, H., et al. The epidemiology of low serum pepsinogen A levels and an international association with gastric cancer rates. (1994) Gastroenterology 107(5): 1335- 44

27. Nomura, A.M., Stemmerman, G.N., Samloff, I.M. Serum pepsinogen I as a predictor of stomach cancer. (1980) Ann Intern Med 93(4): 537- 40

28. Varis, K., Sipponen, P., Laxen, F., et al. Implications of serum pepsinogen I in early endoscopic diagnosis of gastric cancer and dysplasia. (2000) Scand J Gastroenterol 35(9): 950- 6

29. Hallissey, M.T., Dunn. JA, Fielding JWL. Evaluation of pepsinogen A and gastrin-17 as markers of gastric cancer and high-risk pathologic conditions. 1994 Scand J Gastroenterol 29(12): 1129- 34 